\title{
Identification of Defense-Related Rice Genes by Suppression Subtractive Hybridization and Differential Screening
}

\author{
Lizhong Xiong, Min-Woo Lee, Min Qi, and Yinong Yang \\ Department of Plant Pathology, 217 Plant Science Building, University of Arkansas, Fayetteville 72701, \\ U.S.A. \\ Accepted 25 January 2001.
}

\begin{abstract}
Identification of host genes involved in defense responses is one of most critical steps leading to the elucidation of disease resistance mechanisms in plants. In this study, two different cloning strategies were employed to identify defense-related genes from a tropical japonica rice cultivar (Oryza sativa cv. Drew). With the use of bacterial colony arrays, differential screening of a blast fungus (Pyricularia grisea)-induced rice cDNA library led to the isolation of 22 distinct rice genes that are expressed differentially in response to blast infection. Sequence analysis indicates that most of them are full-length cDNAs encoding pathogenesis-related proteins or other relatively abundant proteins. In combination with treatments of cycloheximide plus jasmonic acid (JA) or benzothiadiazole (BTH) in rice seedlings, the polymerase chain reaction-based suppression subtractive hybridization also was conducted to search for immediate early (IE) defense-related genes whose transcription is independent of de novo protein synthesis. The initial screening of only 768 subtracted clones resulted in the identification of $\mathbf{3 4}$ distinct IE genes that are induced by JA, BTH, and/or blast infection. Database searches revealed that these IE genes encode putative mitogenactivated protein kinase, diacylglycerol kinase, zinc finger protein, RelA-SpoT protein, ankyrin-containing protein, ABC transporter, $\beta$-ketoacyl-CoA synthase, and other potential defense-signaling components. Further characterization of these novel IE genes will likely facilitate the elucidation of defense signal transduction in rice plants.
\end{abstract}

Additional keywords: host defense response.

Induction of disease resistance in plants involves a complex network of signal perception, amplification, and transduction, which includes receptor-mediated recognition of invading pathogens, protein phosphorylation cascades, ion fluxes, oxidative bursts, generation of secondary signals, and activation of various defense genes (Yang et al. 1997). During the past decades, extensive efforts have been made to identify signaling molecules as well as regulatory and structural genes in-

Corresponding author: Y. Yang; Telephone: +1-501-575-5635; Fax: +1-501-575-7601; E-mail: yiyang@uark.edu volved in host defense responses. For example, salicylic acid (SA) and jasmonic acid (JA) were found to be key endogenous secondary signals that participate in the activation and/or potentiation of a plant defense response (Dempsey et al. 1999; Dong 1998). A functional analog of SA, benzothiadiazole (BTH), has been used effectively in the field for disease control (Görlach et al. 1996). In addition, a large number of defense-related genes whose products include receptor protein kinases, mitogen-activated protein (MAP) kinases, ion transporters, NADPH oxidase components, transcription factors, pathogenesis-related proteins, and phytoalexin biosynthetic enzymes have been isolated and characterized. Some of these genes may serve as useful targets for genetic engineering of disease resistant crops.

To date, the large majority of research in defense signal transduction has been performed on dicotyledonous species such as tobacco and Arabidopsis, whereas in economically important cereal crops, our understanding of the signaling mechanisms leading to disease resistance is largely unknown (Piffanelli et al. 1999). Only few signaling components such as a small-GTP binding protein and MAP kinase (Kawasaki et al. 1999; He et al. 1999; Kim et al. 1999) as well as a dozen defense genes such as PR-1, $\beta$-glucanase, chitinase, phenylalanine ammonia lyase, and HMG-CoA reductase (Nelson et al. 1994; Simmons et al. 1992; Xu et al. 1996; Zhu and Lamb 1991; Zhu et al. 1995) have been isolated from rice and implicated to be involved in the host defense response. Most recently, differential display analysis has been used to identify a large number of fungal elicitor-responsive genes from rice cell suspensions (Kim et al. 2000). In this study, two experimental approaches were taken to identify defense-related genes from rice seedlings (Fig. 1). We used differential screening of a rice blast fungus (Pyricularia grisea)-induced cDNA library to identify mostly abundant transcripts that are induced or suppressed by fungal infection. In contrast, the use of suppression subtractive hybridization technology (Diatchenko et al. 1996) allowed us to successfully identify a large number of medium or rare transcripts that are induced by JA-, BTH-, and/or blast infection.

To isolate pathogen-induced defense genes, identical bacterial colony arrays were produced on two nylon membranes with a cDNA library made from seedlings of an elite tropical japonica rice cultivar (Oryza sativa L. spp. japonica cv. Drew) 
infected with blast fungus (Lee et al. 2001). Colony hybridization was conducted with ${ }^{32} \mathrm{P}$-labeled total cDNAs generated from blast fungus-infected or uninfected seedlings. A representative differential hybridization result is shown in Figure $2 \mathrm{~A}$, in which 288 clones are arrayed in triplicate. Although most of clones showed similar signal intensity during the differential screenings, some exhibited significant differences in signal intensity, suggesting that they were expressed differen- tially in response to blast infection. Among 12,000 differentially screened clones, 92 clones appeared to be up regulated by blast infection, whereas four clones exhibited down regulation. We partially sequenced the 96 differentially hybridized cDNA clones from the $5^{\prime}$ end and conducted a homology search with the BLAST program (Altschul et al. 1990). Sequence analysis indicates that these 96 clones belong to 31 putative rice genes or gene families, including 28 genes that

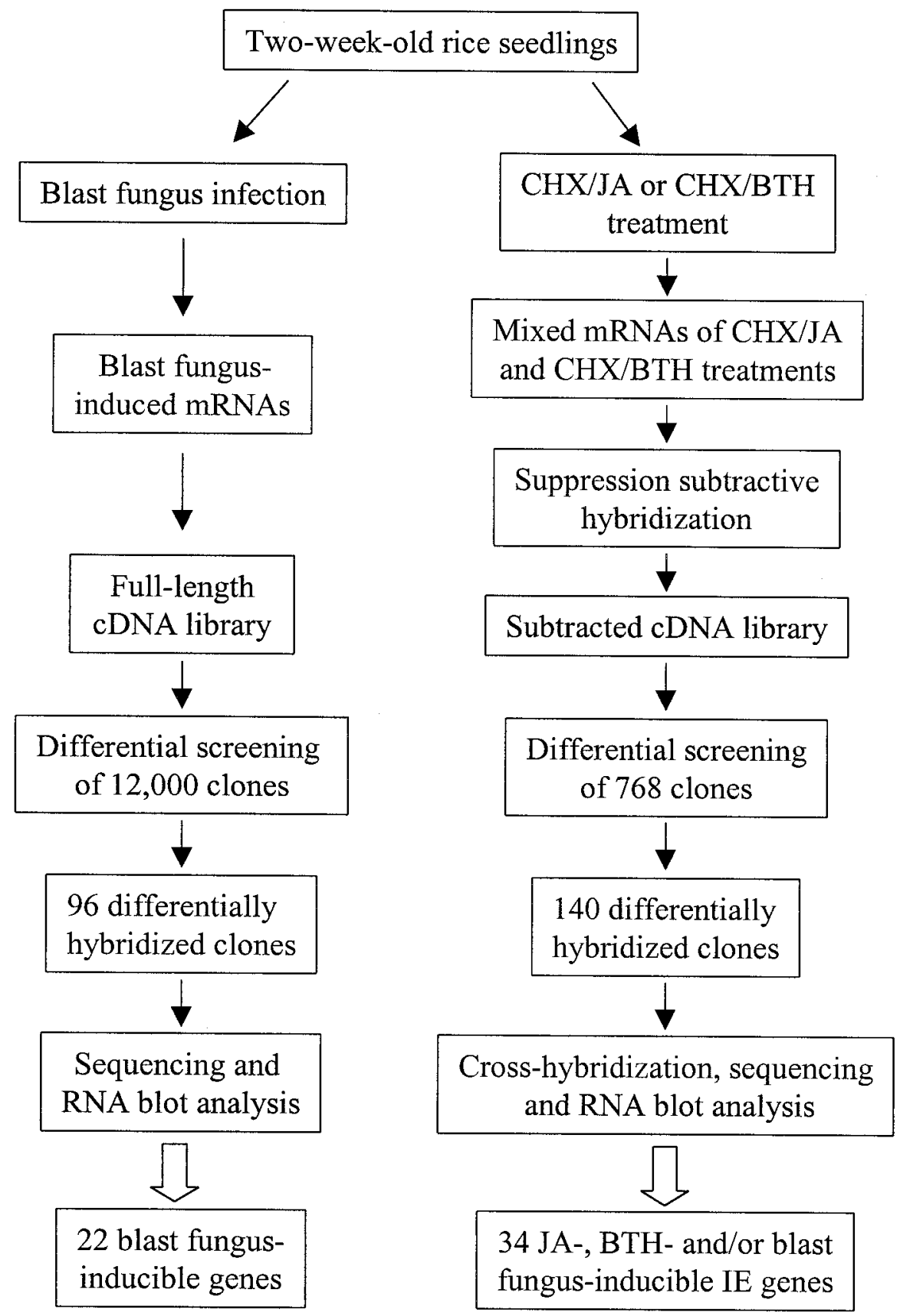

Fig. 1. Flowchart of the experimental designs. Two-week-old rice seedlings were inoculated with rice blast fungus (Pyricularia grisea, 750,000 spores per ml). Total RNAs from leaves at 1,2,3, and 4 days postinfection were extracted separately and then mixed equally for mRNA isolation with the Poly(A) Pure Kit (Ambion, Austin, TX, U.S.A.). Purified mRNAs were used for construction of the blast fungus-induced cDNA library (Lee et al. 2001). For suppression subtractive hybridization, 2-week-old seedlings were pretreated with $0.3 \mathrm{mM}$ cycloheximide $30 \mathrm{~min}$ before $0.2 \mathrm{mM}$ jasmonic acid (JA) or $0.4 \mathrm{mM}$ benzothiadiazole $(\mathrm{BTH})$ treatment. Total mRNAs were isolated from rice leaves $0.5,1$, and $2 \mathrm{~h}$ after JA or BTH treatments. JA- and BTHinduced mRNAs were pooled equally, reverse transcribed to cDNAs, and subjected to subtraction with the PCR-Select Subtraction kit (Clontech, Palo Alto, CA, U.S.A.). Control cDNAs generated from untreated leaves were used for subtraction and differential screening. 
share significant sequence similarity with other plant genes with known functions.

To confirm their differential expression, RNA blot analyses were performed individually with all of the 31 genes, as shown by representative blots in Figure 2B. Twenty-two rice genes were demonstrated to be blast fungus responsive (BFR) (Table 1), including 20 up-regulated genes and two (BFR09 and BFR18) down-regulated genes. Among the 22 genes, eight of them share a high degree of sequence similarity to previously identified pathogenesis-related or stress-inducible genes. They are rice probenazole-induced protein (PBZ1) (BFR01), rice chitinase class III (BFR02), glutathionine Stransferase (GST) (BFR04), ADP ribosylation factor (ARF) (BFR05), pathogenesis-related protein class I (PR-1) (BRF06), metallothionein-like protein (BFR12), lipid transfer protein (BFR14), and late-embryogenesis protein lea-5 (BFR20). The sequence of BFR01 is identical to PBZ1 (Midoh et al. 1996) and therefore considered to be the same gene. At the amino acid level, BFR06 is $100 \%$ identical to a rice basic PR-1 protein (GenBank accession no. U89895) and 56\%

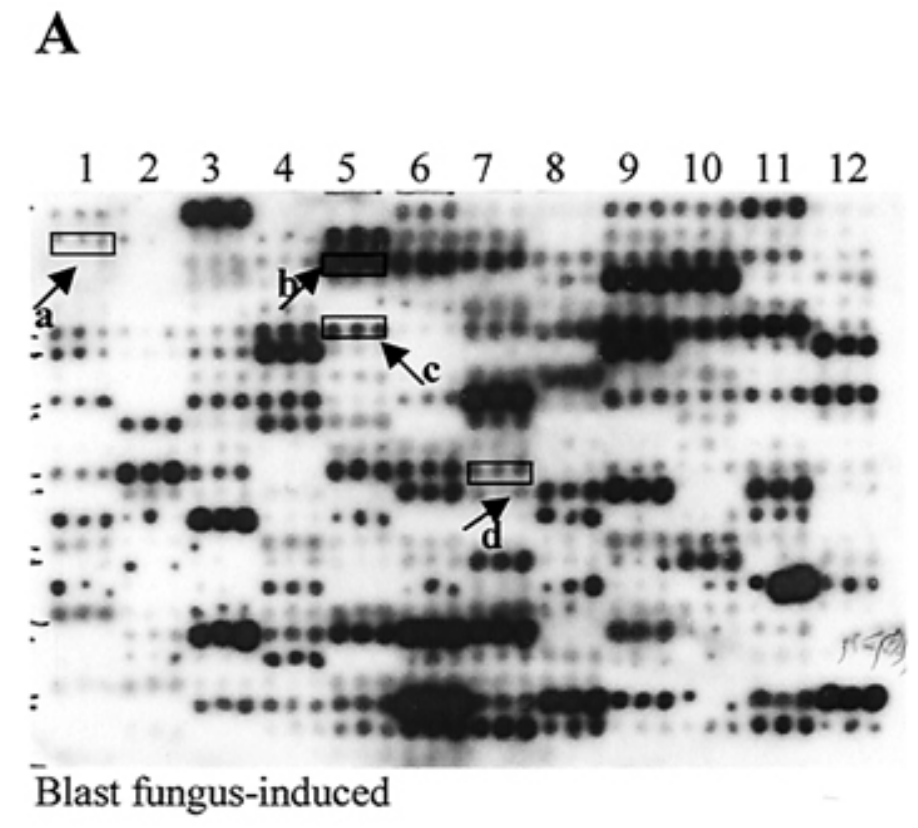

B
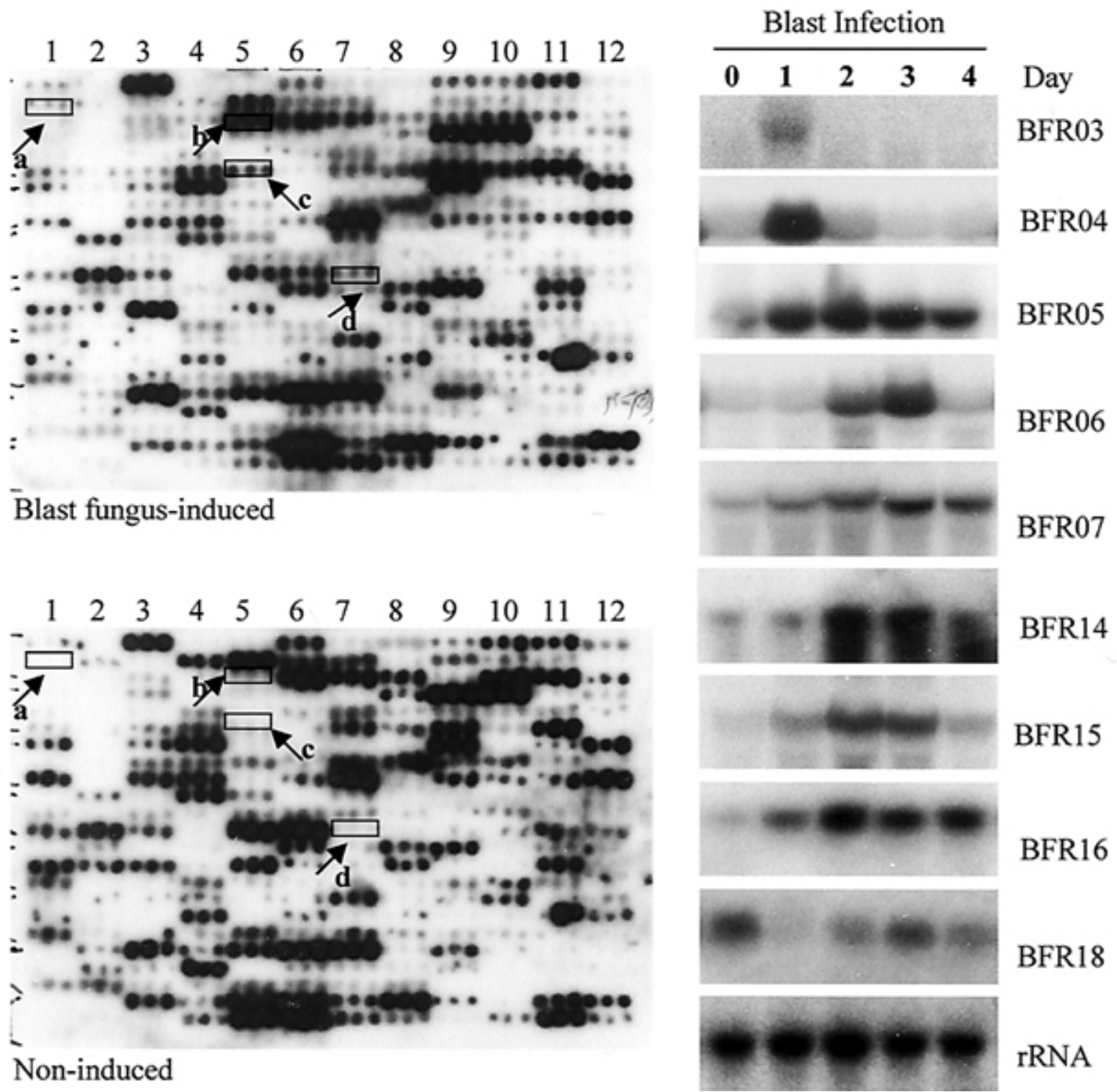

Fig. 2. Identification of rice genes expressed differentially in response to blast infection. A, Differential screening of a blast fungus-induced cDNA library. Bacterial cells carrying cDNA clones were arrayed in triplicate onto nylon membrane with a 96-pin printer and grown on Luria-Bertani agar for 8$12 \mathrm{~h}$. Bacterial colonies were denatured $(0.5 \mathrm{M} \mathrm{NaOH}, 1.5 \mathrm{M} \mathrm{NaCl})$ for $5 \mathrm{~min}$, neutralized $(0.5 \mathrm{M}$ Tris- $\mathrm{HCl}, \mathrm{pH} 7.4 ; 1.5 \mathrm{M} \mathrm{NaCl})$ for $5 \mathrm{~min}$, and UV cross linked. Two identical sets of blots were hybridized with $\left[\alpha-{ }^{32} \mathrm{P}\right]-\mathrm{dCTP}$ labeled control (noninduced) or blast fungus-induced cDNA, respectively. Four differentially hybridized clones corresponding to clone BRF03 (a), BRF04 (b), BRF06 (c), and BRF15 (d) are indicated by boxes. B, RNA blot analysis of differentially expressed rice genes. RNA blots were prepared from total RNAs (10 $\mu \mathrm{g}$ each lane) isolated from water-treated (control) and blast fungus-infected (1,2, 3, and 4 days postinfection) rice seedlings ( 2 weeks old) and hybridized individually with 31 distinct cDNA clones. Nine representative blots are shown. 
identical to an acidic PR-1 protein that was found recently in rice (Agrawal et al. 2000). Clone BFR03 is $84 \%$ identical at the amino acid level to a MYB DNA-binding protein found in Arabidopsis (Schaffer et al. 1998). Interestingly, the transcript of this gene is accumulated quickly at 1 day after blast fungus infection and then dropped to basal level (Fig. 2B). BFR16 and BFR18 clones exhibit significant sequence homology to receptor-like protein kinase genes. RNA blot analyses showed that the expression of BFR16 was induced upon blast fungus infection, whereas transcripts of BFR18 were suppressed at 1 day after blast fungus infection and restored to basal levels of expression (Fig. 2B). Neither clone exhibited significant sequence homology to $X a 21$, a rice resistance gene that also encodes a receptor-like protein kinase (Song et al. 1995). It will be interesting to further characterize these two receptor kinase genes and to determine their role in defense signal transduction and disease resistance. The remaining $11 \mathrm{cDNA}$ clones listed in Table 1 share homology with various types of genes that were previously not known to be induced by pathogen infection. Further experiments are needed to confirm their involvement in rice defense responses.

Most of the genes isolated by the differential screening of the cDNA library are relatively abundant transcripts. To isolate low abundant novel regulatory genes that may encode defense signaling components, we employed suppression subtractive hybridization technology (Diatchenko et al. 1996) in combination with the use of cycloheximide (CHX), an inhibitor of protein synthesis. As demonstrated in Arabidopsis and tobacco systems, many defense signaling components are encoded by immediate early (IE) genes whose transcription is insensitive to $\mathrm{CHX}$ and, therefore, independent of de novo protein synthesis (Horvath and Chua 1996). In comparison, induction of $P R$ and many other defense genes is sensitive to CHX and requires the synthesis of new proteins (Horvath et al. 1998) such as transcription factors. To construct JA- and
BTH-induced subtractive libraries, rice seedlings were pretreated by spraying with $\mathrm{CHX}(0.3 \mathrm{mM})$. Thirty minutes later, seedlings were sprayed with JA $(0.2 \mathrm{mM})$ and BTH $(0.4 \mathrm{mM})$, respectively. The cDNAs from JA- and BTH-treated seedlings were pooled equally and used as the "tester" (containing JAand BTH-induced transcripts). In contrast, cDNAs from untreated leaves were used as the "driver" (control) to subtract noninducible transcripts. The JA- and BTH-induced subtracted cDNA library was constructed with the PCR-Select Subtraction Kit (Clontech, Palo Alto, CA, U.S.A.). Subsequently, cDNA clones containing subtracted cDNA fragments were arrayed on nylon membranes and screened differentially with ${ }^{32} \mathrm{P}$-labeled cDNA probes made from tester and driver mRNAs, respectively (Fig. 3A).

Among the 768 clones screened, 140 clones showed stronger hybridization with the cDNA probe from tester mRNAs than with driver mRNAs. After elimination of redundant clones by cross hybridization, 38 distinct rice genes were identified. To confirm their induction by JA, BTH, and/or blast fungus, RNA blot analyses were performed for each of the 38 cDNA clones (Fig. 3B). Strikingly, 34 of them came out to be JA-, BTH- and/or blast fungus inducible (Table 2), whereas 30 out of 34 were JA inducible. Only 11 were BTH inducible, including eight clones that were induced by JA and BTH. In addition, 10 out of 34 genes were induced by an avirulent isolate of blast fungus. As expected, nearly all of the 34 genes turned out to be $\mathrm{CHX}$ insensitive, suggesting that their induction is independent of de novo protein synthesis.

We sequenced all 34 cDNAs (with insert sizes of 200 to 600 bp) and conducted a homology search with the BLAST program (Altschul et al. 1990). In contrast to the differential screening of the blast fungus-induced cDNA library that uncovered mostly known genes, the majority of IE genes (19 out of 34) identified by subtractive cloning are either homologous

Table 1. Blast fungus-responsive rice genes identified by the differential screening and RNA blot analyses

\begin{tabular}{|c|c|c|c|}
\hline Clone $^{\mathbf{a}}$ & Accession no. & Highest homology ${ }^{b}$ & E-value \\
\hline BFR01 & BF889432 & Probenazole-inducible protein PBZ1[Oryza sativa] (D38170) & $1 \mathrm{E}-100$ \\
\hline BFR02 & BF889433 & Chitinase (EC 3.2.1.14) III [Oryza sativa] (C10728) & $2 \mathrm{E}-34$ \\
\hline BFR03 & BF889434 & MYB-related DNA binding protein [Arabidopsis thaliana] (AC005310) & $1 \mathrm{E}-32$ \\
\hline BFR04 & BF889435 & Glutathione S-transferase TSI-1 [Aegilops tauschii] (AF004358) & $2 \mathrm{E}-26$ \\
\hline BFR05 & BF889436 & ADP-ribosylation factor [Oryza sativa] (D17760) & $1 \mathrm{E}-87$ \\
\hline BFR06 & BF889437 & Pathogenesis-related protein class 1 (PR-1) [Oryza sativa $]$ (U89895) & $1 \mathrm{E}-150$ \\
\hline BFR07 & BF889438 & Glycine-rich cell wall protein (Angrp-1) gene [Oryza sativa] (U40708) & $1 \mathrm{E}-140$ \\
\hline BFR08 & BF889439 & Glycine-rich protein mRNA [Oryza sativa] (AF001894) & $5 \mathrm{E}-58$ \\
\hline BFR09 & BF889440 & Carbonic anhydrase $[$ Oryza sativa $]$ (AB016283) & 1E-69 \\
\hline BFR10 & BF889441 & Phosphoglycerate kinase [Triticum aestivum] (X15232) & $1 \mathrm{E}-103$ \\
\hline BFR11 & BF889442 & Neutral invertase, putative [Arabidopsis thaliana] (AC020580) & $2 \mathrm{E}-7$ \\
\hline BFR12 & BF889443 & Metallothionein-like protein [Oryza sativa] (U18404) & $2 \mathrm{E}-18$ \\
\hline BFR13 & BF889444 & Victorin binding protein [Avena sativa] (U11693) & $6 \mathrm{E}-20$ \\
\hline BFR14 & BF889445 & Lipid transfer protein [Oryza sativa] (AF051369) & 4E-15 \\
\hline BFR15 & BF889446 & Pyruvate dehydrogenase kinase isoform 2 (PDK2) [Zea mays] (AF038586) & $2 \mathrm{E}-48$ \\
\hline BFR16 & BF889447 & Somatic embryogenesis receptor-like kinase [Daucus carota] (U93048) & 9E-33 \\
\hline BFR17 & BF889448 & RNA binding protein [Arabidopsis thaliana] (AB008022) & $1 \mathrm{E}-23$ \\
\hline BFR18 & BF889449 & Putative receptor-like protein kinase [Arabidopsis thaliana] (AL163527) & $2 \mathrm{E}-70$ \\
\hline BFR19 & BF889450 & Glycine-rich RNA-binding protein [Oryza sativa] (AF009411) & $2 \mathrm{E}-12$ \\
\hline BFR20 & BF889451 & Late-embryogenesis protein lea-5 [Nicotiana tabacum] (T01984) & $2 \mathrm{E}-8$ \\
\hline BFR21 & BF889452 & Probable UDP-glucose 4-epimerase [Pyrococcus horikoshii] (H71145) & $2 \mathrm{E}-7$ \\
\hline BFR22 & BF889453 & Ribulose-1,5-bisphosphate carboxylase-oxygenase activase [Oryza sativa] (U74321) & $1 \mathrm{E}-70$ \\
\hline
\end{tabular}

\footnotetext{
${ }^{a}$ Listed are the cDNA clones that are induced or suppressed (BFR09 and BFR18) by blast infection as confirmed by RNA blot analyses.

${ }^{\mathrm{b}}$ Homology search was conducted with the NCBI BLAST program. The closest homolog, together with its origin (species and accession number), is listed for each clone.

${ }^{c}$ The E-value was used to indicate the significance of sequence similarity.
} 
to Arabidopsis genes of unknown function or show no homology with sequences in the databases (Table 2).

The remaining $15 \mathrm{cDNA}$ clones do share sequence homology with the other plant genes of known functions, including some involved in defense signal transduction. Most of them, however, are novel genes that were first identified from rice plants and demonstrated to be associated with defense responses. Clones JBI13 and JBI17 show high sequence homology with a mitogen-activated protein (MAP) kinase from maize and a MAP kinase kinase kinase
(MAP3K) from Arabidopsis, respectively. At the amino acid level, however, JBI13 shares less than $30 \%$ sequence identity (within the sequenced region) with BWMK1, a blast fungus-inducible MAP kinase isolated recently from rice (He et al. 1999). We found that JBI13 was induced by JA, $\mathrm{BTH}$, and blast fungus (Fig. 3B). JBI17 also was JA inducible. Because MAP kinases play an important role in early defense signaling through protein phosphorylation of downstream signaling components, including transcription factors (Hirt 2000), these two novel kinases may be good candi-
A

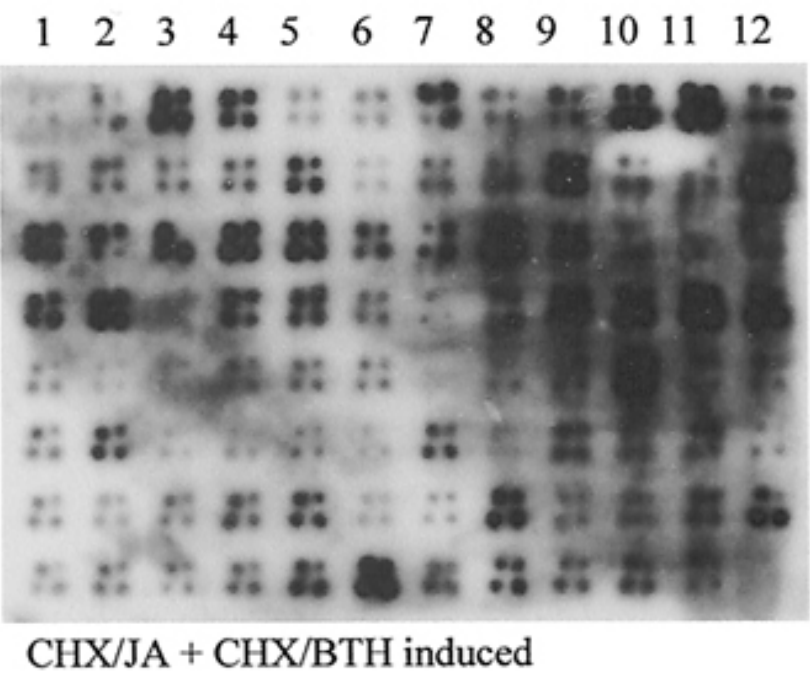

$\begin{array}{llllllllllll}1 & 2 & 3 & 4 & 5 & 6 & 7 & 8 & 9 & 10 & 11 & 12\end{array}$

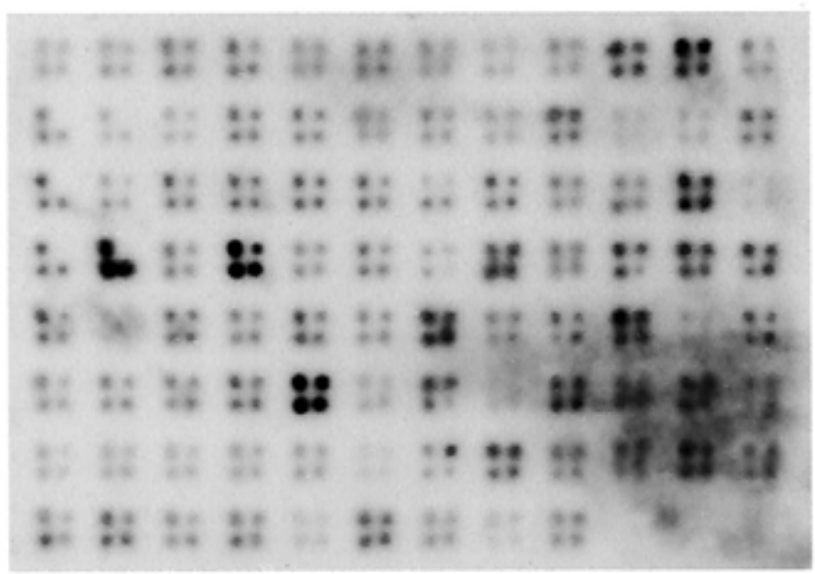

Non-induced
B

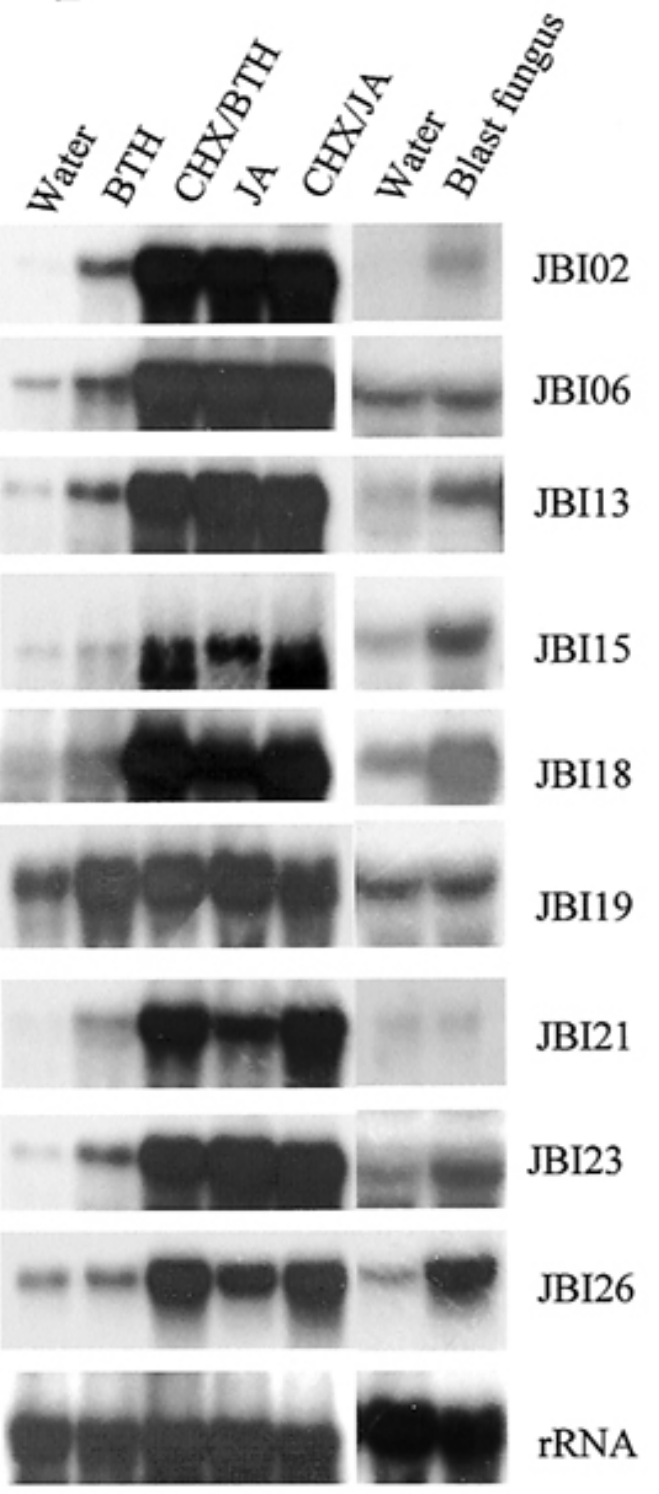

Fig. 3. Identification of rice immediate early (IE) genes induced by jasmonic acid (JA), benzothiadiazole (BTH), and/or blast fungus. A, Screening of differentially expressed cDNA clones from a JA- and BTH-induced subtracted library. Two identical sets of colony arrays were hybridized with $\left[\alpha-{ }^{32} \mathrm{P}\right]-$ dCTP labeled control (water treated) and JA- or BTH-induced cDNAs, respectively. B, RNA blot analysis of JA-, BTH-, and/or blast fungus-induced IE genes. Total RNAs were isolated from 2-week-old rice seedlings treated with water (as control), BTH $(0.4 \mathrm{mM})$, cycloheximide $(\mathrm{CHX}) / \mathrm{BTH}$ (pretreated with $0.3 \mathrm{mM}$ CHX $30 \mathrm{~min}$ prior to the treatment of $0.4 \mathrm{mM} \mathrm{BTH}$ ), $0.2 \mathrm{mM} \mathrm{JA}$, and CHX/JA (pretreated with $0.3 \mathrm{mM}$ CHX 30 min prior to the treatment of $0.2 \mathrm{mM} \mathrm{JA})$. RNA blots were prepared with mixed RNAs ( $10 \mu \mathrm{g}$ per lane) obtained at different time points $(0.5,1$, and $2 \mathrm{~h})$ after each treatment. Also included were $10 \mu \mathrm{g}$ of total RNAs isolated from water-treated (control) or blast fungus-infected seedlings (mixed samples from 1, 2, 3, and 4 days postinfection. These RNA blots were probed individually with 34 distinct cDNA clones that showed differential expression from the array screenings. Nine representative blots are shown. 
dates in which to study the role of MAP kinase cascades in rice defense signaling pathways.

In addition, clone JBI14 encodes a protein with significant homology (84\% identity) to an ankyrin-containing protein from Arabidopsis (GenBank accession no. AC016661). Ankyrin repeats are involved in the protein-protein interaction and have been implicated to function as important motifs in some defense signaling components such as Arabidopsis NPR1 (Cao et al. 1997). Clone JBI15 shares homology with a gene belonging to the zinc-finger family that often encodes signaling components such as transcription factors (Klug 1999; Rushton and Somssich 1998). Clone JBI26 encodes a RelA-SpoT protein that is conserved throughout prokaryotes and eukaryotes. In Escherichia coli, RelA and SpoT determine the level of guanosine tetraphosphate and guanosine pentaphosphate, which are the effector nucleotides of the bacterial stringent response (Cashel et al. 1995). Recently, an Arabidopsis RelA-SpoT homolog was shown to interact physically with the protein encoded by the $R P P 5$ resistance gene and implicated in guanosine phos-

Table 2. Jasmonic acid (JA)-, benzothiadiazole (BTH)-, and/or blast fungus-induced immediate early genes (cDNA fragments) isolated by suppression subtractive hybridization technology

\begin{tabular}{|c|c|c|c|c|c|c|}
\hline \multirow[b]{2}{*}{ Clone } & \multirow[b]{2}{*}{ Accession no. } & \multirow[b]{2}{*}{ Highest homology ${ }^{\text {a }}$} & \multirow[b]{2}{*}{ E-value } & \multicolumn{3}{|c|}{ Inducibility $^{\mathbf{b}}$} \\
\hline & & & & Blast fungus & BTH & JA \\
\hline JBI01 & BF889454 & No homology & - & - & - & + \\
\hline $\mathrm{JBI02}$ & BF889455 & $\begin{array}{l}\text { Putative beta-ketoacyl-CoA synthase [Arabidopsis thaliana] } \\
\text { (AC003105) }\end{array}$ & $\begin{array}{l}2 \mathrm{E}- \\
23\end{array}$ & - & + & + \\
\hline JBI03 & BF889456 & An unknown protein [Arabidopsis thaliana] (AC022354) & $3 \mathrm{E}-5$ & - & + & + \\
\hline JBI04 & BF889457 & No homology & - & + & + & + \\
\hline JBI05 & BF889458 & No homology & - & - & - & + \\
\hline JBI06 & BF889459 & No homology & - & - & - & + \\
\hline JBI07 & BF889460 & No homology & - & - & - & + \\
\hline JBI08 & BF889461 & Hypothetical protein [Arabidopsis thaliana] (T00807) & $\begin{array}{l}5 \mathrm{E}- \\
38\end{array}$ & - & - & + \\
\hline JBI09 & BF889462 & Hypothetical protein [Arabidopsis thaliana] (T06737) & $\begin{array}{l}5 \mathrm{E}- \\
18\end{array}$ & - & - & + \\
\hline JBI10 & BF889463 & No homology & - & - & - & + \\
\hline JBI11 & BF889464 & No homology & - & + & - & - \\
\hline JBI12 & BF889465 & Rubisco activase [Oryza sativa] (P93431) & $\begin{array}{l}4 \mathrm{E}- \\
58\end{array}$ & + & + & + \\
\hline JBI13 & BF889466 & MAP kinase (high homology one from maize) & $\begin{array}{l}1 \mathrm{E}- \\
40\end{array}$ & + & + & + \\
\hline JBI14 & BF889467 & Putative ankyrin-containing protein [Arabidopsis thaliana] ( AC016661) & $\begin{array}{l}2 \mathrm{E}- \\
34\end{array}$ & + & + & - \\
\hline JBI15 & BF889468 & Zinic-finger protein[Triticum aestivum] (S39045) & $\begin{array}{l}9 \mathrm{E}- \\
16\end{array}$ & + & - & + \\
\hline JBI16 & BF889469 & Hypothetical protein from [Arabidopsis thaliana] (AC004484] & $4 \mathrm{E}-9$ & - & - & + \\
\hline JBI17 & BF889470 & MAP3K-like protein kinase [Arabidopsis thaliana] (Z99707) & $\begin{array}{l}6 \mathrm{E}- \\
14\end{array}$ & - & - & + \\
\hline JBI18 & BF889471 & No homology & - & + & - & + \\
\hline JBI19 & BF889472 & Hypothetical protein from [Arabidopsis thaliana] (AC002335) & $\begin{array}{l}5 \mathrm{E}- \\
13\end{array}$ & - & + & + \\
\hline JBI20 & BF889473 & No homology & - & - & - & + \\
\hline JBI21 & BF889474 & NAD-malate dehydrogenase [Nicotiana tabacum] (AJ006974) & $\begin{array}{l}2 \mathrm{E}- \\
47\end{array}$ & - & + & + \\
\hline JBI22 & BF889475 & osNAC6 protein [Oryza sativa] (AB028185) & $\begin{array}{l}\text { E- } \\
155\end{array}$ & + & - & + \\
\hline JBI23 & BF889476 & No homology & & - & + & + \\
\hline JBI24 & BF889477 & An unknown protein [Arabidopsis thaliana] (AC011663) & E-21 & - & - & + \\
\hline JBI25 & BF889478 & No homology & - & + & - & + \\
\hline JBI26 & BF889479 & RSH2: Rel-SpoT homology [Arabidopsis thaliana] (AF225703) & E-32 & + & - & + \\
\hline JBI27 & BF889480 & $\begin{array}{l}\text { ATP-binding cassette (ABC) transporter [Arabidopsis thaliana] } \\
\text { (AC007258) }\end{array}$ & $\begin{array}{l}5 \mathrm{E}- \\
18\end{array}$ & + & + & - \\
\hline JBI28 & BF889481 & $\begin{array}{l}\text { Putative proteasome regulatory subunit [Arabidopsis thaliana] } \\
\text { (AL049657) }\end{array}$ & $\begin{array}{l}6 \mathrm{E}- \\
20\end{array}$ & - & + & - \\
\hline JBI29 & BF889482 & Unknown protein (BnC24B) [Brassica napus] (S37133) & E-20 & + & - & + \\
\hline $\mathrm{JBI} 30$ & BF889483 & Putative diacylglycerol kinase [Arabidopsis thaliana] (AC005724) & $\begin{array}{l}3 \mathrm{E}- \\
53\end{array}$ & + & - & + \\
\hline JBI31 & BF889484 & $\begin{array}{l}\text { NADPH-ferrihemo protein oxido-reductase [Arabidopsis thaliana] } \\
\text { (S21531) }\end{array}$ & $\begin{array}{l}2 \mathrm{E}- \\
12\end{array}$ & - & - & + \\
\hline JBI32 & BF889485 & Unknown protein [Arabidopsis thaliana] (AC006085) & $\begin{array}{l}4 \mathrm{E}- \\
53\end{array}$ & - & - & + \\
\hline JBI33 & BF889486 & Salt stress-induced protein (SalT) [Oryza sativa] (AF001395) & E-80 & + & - & + \\
\hline JBI34 & BF889487 & Glucosyl transferase [Nicotiana tabacum] (AB000623) & $\begin{array}{l}3 \mathrm{E}- \\
18\end{array}$ & - & - & + \\
\hline
\end{tabular}

${ }^{a}$ Homology search was conducted with the NCBI BLAST program. The closest homolog, together with its origin (species and accession number), is listed for each clone. The E-value was used to indicate the significance of sequence similarity.

$\mathrm{b}_{-}=$noninducible; $+=$inducible. 
phate signaling (Van der Biezen et al. 2000). Clone JBI30 shares homology with a diacylglycerol kinase that is involved in inositol phosphate signaling (Van Blitterswijk and Houssa 1999). Clone JBI27 is homologous to an Arabidopsis sequence that encodes a potential ATP-binding cassette (ABC) transporter that may be involved in cellular detoxification mechanisms (Schneider and Hunke 1998). We also obtained a clone (JBI33) with an identical sequence to the rice SalT gene that was previously reported to be salt- and JA-inducible (Claes et al. 1990; Moons et al. 1997). Our result showed it also was induced by blast fungus infection. JBI34, a JA-inducible clone, shares a homology with a putative glucosyl transferase gene that was induced by JA in tobacco suspension cells (GenBank accession no. AB000623). The remaining six clones are homologous to a $\beta$-ketoacyl-CoA synthase (JBI02), ribulose-1,5-bisphosphate carboxylase-oxygenase activase (JBI12), NAD-malate dehydrogenase (JBI21), OsNAC6 protein (JBI22), proteasome regulator subunit (JBI28), or NADPH-ferrihemo protein oxidoreductase (JBI31), respectively. The involvement of these proteins in plant defense responses, however, has previously not been reported.

We employed two different cloning strategies to successfully identify abundant defense genes and medium-rare transcripts of the IE genes that are potentially important to rice defense signaling. The differential screening of 12,000 clones from a blast fungus-induced cDNA library led to the identification of 22 distinct rice genes that are expressed differentially in response to blast infection. Except for a few genes such as the receptor-like protein kinase genes, most are abundant transcripts, including some well-known $P R$ genes. Although the method is not suitable to identify medium-low abundant genes, the differential screening did allow us to directly isolate full-length cDNAs of relatively abundant defense-related genes. By contrast, the use of suppression subtractive hybridization technology greatly facilitated the isolation of cDNA fragments of low or medium abundant defense-related genes. We were able to isolate 34 defenserelated IE genes by screening only 768 clones from the JA/BTH-induced subtracted library. Strikingly, the majority of them are novel rice genes that express at relatively low levels under normal noninduced conditions. Many of these genes encode protein kinases, transcription factors, and other potential signaling components involved in host defense responses. Further characterization and functional analysis of these IE genes should enhance our understanding of defense signal transduction in rice plants.

\section{ACKNOWLEDGMENTS}

We thank T. Tai for sequencing $5^{\prime}$ ends of some blast fungus-induced cDNA clones. We also thank R. Gergerich and K. Korth for critically reviewing the manuscript. This work was supported by the Arkansas Agricultural Experiment Station and the Arkansas Rice Research and Promotion Board.

\section{LITERATURE CITED}

Agrawal, G. K., Jwa, N. S., and Rakwal, R. 2000. A novel rice (Oryza sativa L.) acidic PR1 gene highly responsive to cut, phytohormones, and protein phosphatase inhibitors. Biochem. Biophys. Res. Commun.
274:157-165

Altschul, S. F., Gish, W., Miller, W., Myers, E. W., and Lipman, D. J. 1990. Basic local alignment search tool. J. Mol. Biol. 215:403-410.

Cao, H., Glazebrook, J., Clarke, J. D.,Volko, S., and Dong, X. 1997. The Arabidopsis NPR1 gene that controls systemic acquired resistance encodes a novel protein containing ankyrin repeats. Cell 88:57-63.

Cashel, M., Gentry, D. R., Hernandez, V. J., and Vinella, D. 1995. Pages 1458-1496 in: Escherichia coli and Salmonella: Cellular and Molecular Biology F. C. Neidhardt, ed. American Society of Microbiology, Washington, DC.

Claes, B., Dekeyser, R., Villarroel, R., Van den Bulcke, M., Bauw, G., Van Montagu, M., and Caplan, A. 1990. Characterization of a rice gene showing organ-specific expression in response to salt stress and drought. Plant Cell 2:19-27.

Dempsey, D., Shah, J., and Klessig, D. F. 1999. Salicylic acid and disease resistance in plants. Crit. Rev. Plant Sci. 18:547-575.

Diatchenko, L., Lau, Y. F., Campbell, A. P., Chenchik, A., Moqadam, F., Huang, B., Lukyanov, S., Lukyanov, K., Gurskaya, N., Sverdlov, E. D., and Siebert, P. D. 1996. Suppression subtractive hybridization: A method for generating differentially regulated or tissuespecific cDNA probes and libraries. Proc. Natl. Acad. Sci. USA 93:6025-6030.

Dong, X. 1998. SA, JA, ethylene, and disease resistance in plants. Curr. Opin. Plant Biol. 1:316-323.

Görlach, J., Volrath, S., Knauf-Beiter, G., Hengy, G., Beckhove, U., Kogel, K. H., Oostendorp, M., Staub, T., Ward, E., Kessmann, H., and Ryals, J. 1996. Benzothiadiazole, a novel class of inducers of systemic acquired resistance, activates gene expression and disease resistance in wheat. Plant Cell 8:629-643.

He, C., Fong, S. H. T., Yang, D., and Wang, G.-L. 1999. BWMK1, a novel MAP kinase induced by fungal infection and mechanical wounding in rice. Mol. Plant Microbe Interact. 12:1064-1073

Hirt, H. 2000. MAP kinases in plant signal transduction. Results Probl. Cell Differ. 27:1-9.

Horvath, D. M., and Chua, N. H. 1996. Identification of an immediateearly salicylic acid-inducible tobacco gene and characterization of induction by other compounds. Plant Mol. Biol. 31:1061-1072.

Horvath, D. M., Huang, D. J., and Chua, N.-H. 1998. Four classes of salicylate-induced tobacco genes. Mol. Plant-Microbe Interact. 11:895-905.

Kawasaki, T., Henmi. K., Ono. E., Hatakeyama. S., Iwano, M., Satoh, H., and Shimamoto K. 1999. The small GTP-binding protein Rac is a regulator of cell death in plants. Proc. Natl. Acad. Sci. USA 96:1092210926.

Kim, C. Y., Lee, S.-H., Park, H. C., Bae, C. G., Cheong, Y. H., Choi, Y. J., Han, C., Lee, S. Y., Lim, C. O., and Cho, M. J. 2000. Identification of rice blast fungal elicitor-responsive genes by differential display analysis. Mol. Plant-Microbe Interact. 13:470-474.

Kim, W. Y., Kim, C. Y., Cheong, N. E., Choi, Y. O., Lee, K. O., Lee, S. H., Park, J. B., Nakano, A., Bahk, J. D., Cho, M. J., and Lee, S. Y. 1999. Characterization of two fungal-elicitor-induced rice cDNAs encoding functional homologues of the rab-specific GDP-dissociation inhibitor. Planta 210:143-149.

Klug, A. 1999. Zinc finger peptides for the regulation of gene expression. J. Mol. Biol. 293:215-218.

Lee, M. W., Qi, M., and Yang, Y. 2001. A novel jasmonic acid-inducible rice $m y b$ gene associates with fungal infection and host cell death. Mol. Plant-Microbe Interact. 14:527-535.

Midoh, N., and Iwata, M. 1996. Cloning and characterization of a probenazole-inducible gene for an intracellular pathogenesis-related protein in rice. Plant Cell Physiol. 37:9-18.

Moons, A., Gielen, J., Vandekerckhove, J., Van der Straeten, D., Gheysen, G., and Van Montagu, M. 1997. An abscisic-acid- and salt-stress-responsive rice cDNA from a novel plant gene family. Planta 202:443-454.

Nelson, A. J., Doerner, P. W., Zhu, Q., and Lamb, C. J. 1994. Isolation of a monocot 3-hydroxy-3-methylglutaryl coenzyme A reductase gene that is elicitor-inducible. Plant Mol. Biol. 25:401-412.

Piffanelli, P., Devoto, A., and Schulze-Lefert, P. 1999. Defense signaling pathways in cereals. Curr. Opin. Plant Biol. 2:295-300.

Rushton, P. J., and Somssich, I. E. 1998. Transcriptional control of plant genes responsive to pathogens. Curr. Opin. Plant Biol. 1:311315 . 
Schaffer, R., Ramsay, N., Samach, A., Corden, S., Putterill, J., Carre, I. A., and Coupland, G. 1998. The late elongated hypocotyl mutation of Arabidopsis disrupts circadian rhythms and the photoperiodic control of flowering. Cell 93:1219-1229.

Schneider, E., and Hunke, S. 1998. ATP-binding-cassette (ABC) transport systems: functional and structural aspects of the ATP-hydrolyzing subunits/domains. FEMS Microbiol. Rev. 22:1-20

Simmons, C. R, Litts, J. C., Huang, N., and Rodriguez, R. L. 1992. Structure of a rice beta-glucanase gene regulated by ethylene, cytokinin, wounding, salicylic acid and fungal elicitors. Plant Mol. Biol. 18:33-45.

Song, W. Y., Wang, G. L., Chen, L. L., Kim, H. S., Pi, L. Y., Holsten, T., Gardner, J., Wang, B., Zhai, W. X., Zhu, L. H., Fauquet, C., and Ronald, P. 1995. A receptor kinase-like protein encoded by the rice disease resistance gene, Xa21. Science 270:1804-1806.
Van Blitterswijk, W. J., and Houssa, B. 1999. Diacylglycerol kinases in signal transduction. Chem. Phys. Lipids 98:95-108.

Van der Biezen, E. A., Sun, J., Coleman, M. J., Bibb, M. J., and Jones, J. D. 2000. Arabidopsis RelA/SpoT homologs implicate (p)ppGpp in plant signaling. Proc. Natl. Acad. Sci. USA 97:3747-3752.

Xu, Y., Zhu, Q., Panbangred, W., Shirasu, K., and Lamb, C. 1996. Regulation, expression and function of a new basic chitinase gene in rice (Oryza sativa L.). Plant Mol. Biol. 30:387-401.

Yang, Y., Shah, J., and Klessig, D. F. 1997. Signal perception and transduction in plant defense responses. Genes Dev. 11:1621-1639.

Zhu, Q., Dabi, T., Beeche, A., Yamamoto, R., Lawton, M. A., and Lamb, C. 1995. Cloning and properties of a rice gene encoding phenylalanine ammonia-lyase. Plant Mol. Biol. 29:535-550.

Zhu, Q., and Lamb, C. J. 1991. Isolation and characterization of a rice gene encoding a basic chitinase. Mol. Gen. Genet. 226:289-296. 